\title{
Advances in Modelling and Prediction on the Impact of Human Activities and Extreme Events on Environments
}

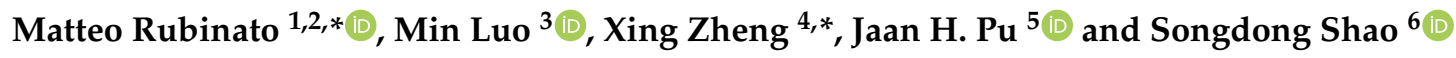 \\ 1 Faculty of Engineering, Environment \& Computing, School of Energy, Construction and Environment, \\ Coventry University, Coventry CV1 5FB, UK \\ 2 Centre for Agroecology, Water and Resilience, Coventry University, Wolston Lane, Coventry CV8 3LG, UK \\ 3 Zienkiewicz Centre for Computational Engineering, College of Engineering, Swansea University, \\ Swansea SA1 8EN, UK; min.luo@swansea.ac.uk \\ 4 College of Shipbuilding Engineering, Harbin Engineering University, Harbin 150001, China \\ 5 Faculty of Engineering and Informatics, University of Bradford, Bradford BD7 1DP, UK; \\ j.h.pu1@bradford.ac.uk \\ 6 Department of Civil and Structural Engineering, University of Sheffield, Sheffield S1 3JD, UK; \\ s.shao@sheffield.ac.uk \\ * Correspondence: matteo.rubinato@coventry.ac.uk (M.R.); zhengxing@hrbeu.edu.cn (X.Z.); \\ Tel.: +44-(0)24-7765-0887 (M.R.); +86-(0)451-8256-8147 (X.Z.)
}

Received: 8 June 2020; Accepted: 14 June 2020; Published: 22 June 2020

\begin{abstract}
Fast urbanization and industrialization have progressively caused severe impacts on mountainous, river, and coastal environments, and have increased the risks for people living in these areas. Human activities have changed ecosystems hence it is important to determine ways to predict these consequences to enable the preservation and restoration of these key areas. Furthermore, extreme events attributed to climate change are becoming more frequent, aggravating the entire scenario and introducing ulterior uncertainties on the accurate and efficient management of these areas to protect the environment as well as the health and safety of people. In actual fact, climate change is altering rain patterns and causing extreme heat, as well as inducing other weather mutations. All these lead to more frequent natural disasters such as flood events, erosions, and the contamination and spreading of pollutants. Therefore, efforts need to be devoted to investigate the underlying causes, and to identify feasible mitigation and adaptation strategies to reduce negative impacts on both the environment and citizens. To contribute towards this aim, the selected papers in this Special Issue covered a wide range of issues that are mainly relevant to: (i) the numerical and experimental characterization of complex flow conditions under specific circumstances induced by the natural hazards; (ii) the effect of climate change on the hydrological processes in mountainous, river, and coastal environments, (iii) the protection of ecosystems and the restoration of areas damaged by the effects of climate change and human activities.
\end{abstract}

Keywords: experimental modelling; numerical modelling; scouring; sediment transport; smoothed-particle hydrodynamics; flooding; dam-break; debris flows; climate change; urban evolution; natural hazard

\section{Introduction}

During the last few decades, urbanization, which refers to an increase in population and the amount of industrialization of a settlement, has become one of the dominant forms of landscape disturbance [1]. Over the years, more people are moving from rural to urban areas, increasing their 
density and inducing continuous land changes that indirectly inflict many unwanted consequences such as land insecurity [2,3], worsening water quality [4], poor air quality [5,6], and adverse hydrological processes [7-9] and local ecosystems [10,11]. The impacts of anthropogenic development have affected over $75 \%$ of Earth's land surface [12] and recent studies have confirmed that urbanization has also had an impact on precipitation rates, increasing their spatial variability and intensification $[13,14]$.

Climate interacts to influence the quantity and quality of Earth's environment, aggravating the entire scenario [15-17]. Extreme events are becoming more frequent and their consequences are spreading worldwide. Due to a rise in sea levels, which are expected to increase by between 0.07 and $0.12 \mathrm{~m}$ during the 21st century [18], communities living near coastal areas are facing potential multi-hazard threats. Furthermore, due to the increased extreme rainfall events, both urban and rural catchments are subject to continuous risks of flooding [19], where properties can be inundated and, in combination with the critical events and geographical characteristics such as steep slopes and proximity of houses near mountainous rivers, human losses caused by the landslides and debris flows can be escalated [20-24]. About 3.8 million $\mathrm{km}^{2}$ and 790 million people in the world are living in relatively high exposure to at least two hazards, while about 0.5 million $\mathrm{km}^{2}$ and 105 million people to three or more hazards (e.g., floods, droughts, tropical storms, earthquakes, volcanoes, and landslides), according to a report of the World Bank on the main hotspots of natural hazards [25]. Considering the variety of effects and areas at risk, climate change is likely to further increase community exposure to multiple risks, affecting the magnitude, frequency, and spatial distribution of hazardous and disastrous events [25,26].

Dated back in 2012, governments had established a set of Sustainable Development Goals (SDGs) that were integrated into the follow-up of Millennium Development Goals (MDGs) after their 2015 deadline. SDG 13 considers both adaptation and mitigation to climate change and targets at strengthening resilience, improving monitoring, and integrating measures into local and national planning policies [27]. Additionally, SDG 11 aims at making cities and human settlements inclusive, safe, resilient, and sustainable [28].

To contribute to filling the needs identified within these SDGs, this Special Issue aimed at gathering the latest developments in advanced numerical and experimental modeling and other technologies, to provide a better understanding of the specific phenomena associated with natural disasters, and to predict and evaluate changes in river, coastal, and mountainous environments induced by extreme events and human activities. The articles published within this Special Issue aimed to aid local and national authorities on the design and implementation of mitigation strategies, thus providing tools that could secure a more accurate management of their environmental areas.

\section{Summary of this Special Issue}

Climate change has caused a transformation in the rainfall patterns, and the rainfall amount and intensity had a great impact on the hydrological dynamics across the world. To investigate this impact of climate change in karst regions, which are widely distributed in southwest China, Li et al. [29] have conducted experimental work to identify close relationship between subsurface and underground fissure flows with various rainfall intensities and bedrock degrees. Results obtained from this study have confirmed that under light rainfall conditions $\left(30 \mathrm{~mm} \mathrm{~h}^{-1}\right)$, the hydrological processes observed were typical of Dunne overland flows; however, under moderate $\left(60 \mathrm{~mm} \mathrm{~h}^{-1}\right)$ and high $\left(90 \mathrm{~mm} \mathrm{~h}^{-1}\right)$ rainfall conditions, the hydrological processes were typical of Horton overland flows [29].

Climate change and catchment modification induced by human activities are the main drivers, and play a significant role worldwide in the dramatic variation of water levels in lakes. A case study on Qinghai Lake, the largest inland saline lake on the Tibetan Plateau, was presented by Fang et al. [30] and the meteorological and land use data collected between 1960 and 2016 have been analyzed to investigate the effect of climate change and human activities on this lake. Results obtained have demonstrated that the water level of Qinghai Lake declined between 1960 and 2004, and since then has risen continuously and gradually, due to changes in evaporation, precipitation, and consequent surface 
runoff associated with climate changes and catchment modifications. Moreover, the changes in rainfall patterns and magnitudes generated by climate change may have also had an effect on runoff and soil erosion processes. Ran et al. [31] have conducted a study aiming to understand how various rainfall patterns (constant, increasing, decreasing, rising-falling, and falling-rising) affect these processes, with a particular focus on the slopes with a wide range of gradients $\left(5^{\circ}\right.$ to $\left.40^{\circ}\right)$ and length scales $(25 \mathrm{~m}$ to $200 \mathrm{~m}$ ). Results have identified a critical slope, $15^{\circ}$, which was independent of the rainfall pattern and slope length. However, it has been found that the critical slope of soil erosion amounts decreased from $35^{\circ}$ to $25^{\circ}$, with an increasing projective slope length [31].

The increase of sediment erosions induced by higher rainfall intensities, together with the effects caused by human activities related to the deforestation and expansion of farmland, have recently been considered as a major issue for the normal functionality of dams and river embankments [32]. These engineering structures are important assets that need to be regularly checked because they could generate significant damages to the surrounding environment as well as to the people living in nearby areas once they fail. Multiple papers have been submitted on this topic within this Special Issue.

Check dams were numerically investigated by Tang et al. [33] To support the development of future planning and management strategies in terms of soil and water conservation, the hydrologic response changes and the sedimentary processes caused by a check dam system were simulated [33], and the results showed that a check dam can significantly alter water redistribution in the catchment and influence the groundwater table in different periods. Furthermore, Tang et al. [34] investigated the influences of filled check dams with six different deployment strategies in a Loess Plateau catchment and compared them with the no-dam and real scenarios. The results showed that the filled check dams were still able to effectively reduce the flood peak $\left(Q_{p}\right)$ by $31 \%$ to $93 \%$ under different deployment strategies.

Dam as well as embankment failures can also be caused by the process of internal erosion. To date, various types of internal erosion have been identified: concentrated leak erosion, contact erosion, backward erosion, and suffusion. Suffusion constitutes a major threat to the foundation of a dam, and its likelihood is usually determined by the internal stability of soils and the interaction of soil particles with seepage flows. A study was presented by Feng et al. [35], where a numerical model was developed to simulate the suffusion process, thus assessing the internal stability of the dam. Results have confirmed that the suffusion effect is closely related to the specific grain size distribution of the soils [35].

Flooding due to dam break has potentially disastrous consequences and multiple studies have been conducted to replicate the hydrodynamics of this phenomenon [36-38]. Due to frequent field events during the last decade, it is becoming increasingly important to understand the key physics behind the dam break. Thanks to the latest advances in the use of high performance computing techniques to accelerate the computational fluid dynamics (CFD) codes, it is now possible to simulate the natural hazards associated with the rapidly varied flows of both water and dense granular mixtures, together with the sediment erosion and bed load transport $[39,40]$. Due to its Lagrangian nature, the Smoothed Particle Hydrodynamics (SPH) method has been used to solve a variety of fluid-dynamic processes with highly nonlinear features such as debris flow, wave breaking and impact, multi-phase mixing, jet impact, flooding and tsunami inundation, and fluid-structure interactions [41]. For example, Wu et al. [41] applied the SPH method to solve two-dimensional Shallow Water Equations (SWEs), and the solution proposed was validated against two open-source case studies of a dry-bed dam break and another dam break with a rectangular obstacle downstream. In addition to the improvement and optimization of the numerical algorithm, a CPU-OpenMP parallel computing technique was also implemented to enhance the model performance.

In this Special Issue, the SPH method was also vigorously applied to investigate another cause of the natural disaster, i.e., debris flows, which are characterized by high density, impact force and destructiveness, and complexity of the materials they are made of [42]. The numerical simulations involved three different soil configurations and the results obtained by applying the modifications included into the SPH model clearly demonstrated that the configuration where fine and coarse 
particles are fully mixed, with no specific layering, produced more fluctuations and instability of the debris flow. This SPH modeling work has provided a better understanding on the mechanism of intermittent debris flows [42].

Another study was also presented on the SPH method applied to simulate liquid sloshing in a 2D tank with water jet flows as presented by Jiang et al. [43] The study compared the liquid sloshing under different conditions to analyze the effects of excitation frequency and water jet on the impact pressures. Results obtained firstly confirmed the applicability of the SPH method to accurately replicate these features and, secondly, demonstrated that the water jet flows can significantly affect the impact pressures on the wall caused by the violent sloshing [43].

To protect residential areas from the river flooding, embankments are usually constructed as a defense. If well constructed, these riverside embankments can be relatively effective in stopping the water spilling onto the adjacent lands. These structures are equally a very good benefit to the wildlife habitat (e.g., species-rich grassland or riparian woodland). However, being similar to the dam-break, the failure of these systems can also lead to devastating and fatal consequences.

To address this knowledge gap, a study was published in this Special Issue where a numerical simulation was conducted to investigate the failure processes of a homogeneous embankment due to the flow overtopping [44]. The good agreement between experimental and numerical results confirmed the accuracy of the employed numerical approach based on a double-point two-phase material point method (MPM) considering the water-soil interactions and seepage effects [44]. Within the same river environment, sediment erosions can occur on the riverbed, on the side-bank of the river and even on some local areas, such as those around the piers that are built along the river to support the bridges. Pandey et al. [45] conducted experiments to analyze the maximum equilibrium between the scour depth and the scour process in an armored streambed. It was found that the variation of the maximum dimensionless scour depth with the dimensionless armor particle size depends on the densimetric particle Froude number $\left(F r_{d 50}\right)$. Sediments are eroded and transported by the water along the river and their deposition, suspension and transport are regulated and continuously modified by the turbulence and other flow structures [45]. To provide better understanding on the coupled effects of sediment inertia and stratification on the pattern of secondary current in bend-flows, a study was published by Yang et al. [46] to evaluate a full 3D numerical model. The sediment inertia effect, as well as the stratification effect induced by the non-uniform distribution of suspended sediments, was accounted for by adopting the hydrodynamic equations without the Boussinesq approximation. The numerical results demonstrated that sediment stratification effects enhanced the intensity of secondary flow via reducing the eddy viscosity, while the sediment inertia effects suppressed it [46]. On the other hand, the sediments may be in contact with the emergent vegetations across the river, which also play an important role in affecting the turbulence, velocity pattern, resistance, and sediment transport, with consequent morphological changes. A well-conducted review on the hydrodynamics of free surface flows in an emergent vegetated channel was presented by Maji et al. [47] The authors have highlighted the progresses in a wide range of field, laboratory, and numerical investigations on the turbulent flow within different emergent vegetations, and focused on the vegetation-induced flow field, velocity distribution, and structure and drag effects [47]. This review is beneficial for the local and national authorities in charge of restoring the river environments and implementing the strategies for the attenuation of river flooding.

Rivers and lakes are the environments that provide a complex interaction among dissimilar water resources, which can be affected by both climate change and human activities, and they are rich of various ecosystems. A study provided by Ma et al. [48] focused on the ecosystem services in Dongting Lake area, investigating snail control and schistosomiasis prevention, water yield, soil conservation, and carbon storage. They evaluated plenty of data collected between 2005 and 2015 by using ArcGIS 10.2 and InVEST models [48]. This study has confirmed that the evapotranspiration, precipitation, soil erodibility, and rainfall erosivity significantly influenced some of the ecosystem services in the study area. Nevertheless, to implement satisfactory management strategies in these environments, 
it is necessary to fully understand the magnitude of the flows, and their duration and frequency, because these could have a huge impact on the ecological water demand. To further analyze these features, Zhou et al. [49] created a multi-scale coupled ecological dispatching model based on the decomposition-coordination principle, where they considered the multi-scale features of the ecological water demand. Results showed that the degree of hydrologic alteration of small-scale ecological flow regimes and the daily stream flows can be accurately predicted by their proposed model, demonstrating the impact of hydrologic alterations on the reliability of the water supply [49].

Hydrodynamic modelling is also one of the most relevant challenges in marine and ocean engineering for protecting the coastal areas from erosion and flooding [50], as well as identifying the sources of energy that could be generated by the specific wave conditions. In this Special Issue, the popular mesh-free SPH method was applied to investigate the flow behavior inside and outside a porous structure under continuous wave actions [51]. To construct an accurate and efficient model, a unified set of flow equations was solved for both the porous flow region and the outside free flow region, with the interface boundary condition being automatically satisfied. The SPH simulations have been used to analyze the flow structures near the porous obstacle, with a focus on the longitudinal and vertical velocity distributions in the complex vortex and eddy areas. The study provided an innovative insight into the mathematical modelling of fluid-structure interactions (FSI) in a practical coastal environment [51].

Oceans are subjected to a very challenging environment, because they are characterized by a variety of wave conditions, from freak to tsunami waves. Therefore, $\mathrm{Xu}$ et al. [52] conducted an experimental work aiming to better understand the generation and mechanism of those extreme waves, as well as their potential hydrodynamic loads on the floating or fixed ocean structures in extreme sea environments. In this study, a series of focusing waves based on the two newly proposed wave amplitude spectra (i.e., QCWA and QCWS spectra) were tested in a physical wave tank, demonstrating that different spectra can lead to different wave crest elevations and locations. The spectral analysis results showed that the wave nonlinearity also plays an important role in the focusing wave generation for one type of the spectrum, whereas the redistribution of wave energy in the input frequency range significantly affects the focusing wave generation for another type of the spectrum. In addition, Jin et al. [53] presented a 2D numerical model to investigate the vortex-induced vibrations (VIVs) for a submerged floating tunnel (SFT) with different Reynolds numbers (Re), by solving the incompressible viscous Reynolds-averaged Navier-Stokes (RANS) equations in the frame of the Abitrary Lagrangian Eulerian (ALE) approach. The computational results showed that the Re numbers have a great influence not only on the vibration amplitude and the lock-in region, but also on the force coefficient on the SFT. Then it was further concluded that when the size of SFT is small, or when the flow velocity action on the structure is slow, the force coefficient and the lock-in region are relatively large, while when the size is large or when the velocity is fast, these key parameter values are relatively small [53].

Last but not the least, aligned with the modern needs to identify renewable energy/energy efficiency and expand energy access, Yu et al. [54] focused on wind turbines and the effect of turbine blade deformations with relevant lifespan issues. The developed technique combined the actuator line model (ALM) with a beam solver for use in the wind turbine blade design. A popular open source code, OpenFOAM, was used to investigate the performance of the National Renewable Energy Laboratory $5 \mathrm{MW}$ wind turbine in terms of its power, thrust, and blade tip displacement, leading to insights on the negative influences of tower shadow effect on the power production. The well-calibrated model has been found to be capable of obtaining acceptable predictions on a range of wind turbine parameters for practical purposes.

Besides, it is worth mentioning that other state-of-the-art numerical schemes are also being developed by the same research group aiming to improve the applicability of the mesh-free methods in coastal and ocean engineering, including the recent benchmark works on implementing the Taylor series consistency principle to treat the pressure gradient term in 3D Navier-Stokes equations [55] 
and developing the advanced macroscopic equations of mass and momentum for the interaction at an interface of flow with porous media [56].

\section{Conclusions}

This Special Issue has covered a wide range of contemporary issues on the impacts to the environments generated by global climate changes and human activities. The studies in this Special Issue provide timely inputs into growing needs across the world. Due to the continuously changing circumstances, future trends in the management of mountainous, river, and coastal environments will need to be dynamic processes based on adaptive management. Consequently, it is a priority to keep assessing whether the existing management approaches are still effective in response to the increasing interactions between the environments, the land use, and climate change on the global stage.

Further research should focus on understanding the responses of environments under the influence of climate change and human activities separately, as well as their combined effects, in order to develop more robust adaptation strategies and policies for environmental protection, planning, and management. Decision-makers need to have effective tools to better predict the causes of these natural hazards as well as the impacts that they can inflict onto environments. Policy-makers should then direct significant efforts to shape their guidelines towards a more sustainable societal progress including both the protection of the environment and the restoration of the areas that have been damaged by climate change and anthropogenic development; indeed, excessive deforestation or installation of dams with improper regulation could lead to negative impacts of a similar magnitude to those caused by climate change.

Targeting solutions to adapt to climate change and human impact could also lead to an improvement of the quality of life across the world. For example, to tackle urban, coastal, and river flooding, living communities can be more wisely managed by expanding green spaces that could help reduce flood risks and attenuate the peak flows. At the same time, these green areas could also serve as recreational spaces that contribute to human health and well-being, and could help improve local biodiversity. It is imperative to note that uncertainties should always be included so as not to underestimate the adverse impacts on the environments and there should always be frequent communications among stakeholders on a global scale to nurture the exchange of knowledge towards more joint collaborations.

Acknowledgments: The authors of this editorial and the guest editors of this Special Issue would like to thank all the authors for their notable contributions as well as all the reviewers for devoting their time and effort to reviewing the manuscripts. Finally, our special thanks go to the Water Editorial team, in particular Senior Assistant Editor Janelee Li, for their great support during the processing of the submitted manuscripts.

Funding: The authors want to acknowledge the following grants: (1) The National Natural Science Foundation of China (Grant No: 51879051); (2) The Belt and Road Special Foundation of the State Key Laboratory of Hydrology-Water Resources and Hydraulic Engineering (Grant No: 2019491711); (3) The Open Research Fund of the State Key Laboratory of Hydraulics and Mountain River Engineering in Sichuan University (Grant No: SKHL1710 and SKHL1712); and (4) Qinghai Science and Technology Projects (Grant No: 2017-ZJ-Y01).

Conflicts of Interest: The authors declare no conflict of interest.

\section{References}

1. Price, S.J.; Dorcas, M.E.; Gallant, A.L.; Klaver, R.W.; Wilson, J.D. Three decades of urbanization: Estimating the impact of land-cover change on stream salamander populations. Biol. Conserv. 2006, 133, 436-441. [CrossRef]

2. Abass, K.; Adanu, S.K.; Agyemang, S. Peri-urbanisation and loss of arable land in Kumasi Metropolis in three decades: Evidence from remote sensing image analysis. Land Use Policy 2018, 72, 470-479. [CrossRef]

3. Sussman, H.S.; Raghavendra, A.; Zhou, L. Impacts of increased urbanization on surface temperature, vegetation, and aerosols over Bengaluru, India. Remote Sens. Appl. Soc. Environ. 2019, 16, 100261. [CrossRef]

4. Singh, S.; Hassan, S.M.T.; Hassan, M.; Bharti, N. Urbanisation and water insecurity in the Hindy Kush Himalaya: Insights from Bangladesh, India, Nepal and Pakistan. Water Policy 2020, 22, 9-32. [CrossRef] 
5. Yu, S.; Lu, H. Relationship between urbanization and pollutant emissions in transboundary river basins under the strategy of the Belt and Road Initiative. Chemosphere 2018, 203, 11-20. [CrossRef]

6. Xu, X.; Gonzalez, J.E.; Shen, S.; Miao, S.; Dou, J. Impacts of urbanization and air pollution on building energy demands-Beijing case study. Appl. Energy 2018, 225, 98-109. [CrossRef]

7. Locatelli, L.; Mark, O.; Mikkelsen, P.S.; Nielsen, K.A.; Deletic, A.; Roldin, M.; Binning, P.J. Hydrologic impact of urbanization with extensive stormwater infiltration. J. Hydrol. 2017, 544, 524-537. [CrossRef]

8. Oudin, L.; Salavati, B.; Furusho-Percot, C.; Ribstein, P.; Saadi, M. Hydrological impacts of urbanization at the catchment scale. J. Hydrol. 2018, 559, 774-786. [CrossRef]

9. Luo, J.; Zhou, X.; Rubinato, M.; Li, G.; Tian, Y.; Zhou, J. Impact of multiple vegetation covers on surface runoff and sediment yield in the small basin of Nverzhai, Hunan Province, China. Forests 2020, 11, 329. [CrossRef]

10. Garcia-Nieto, A.P.; Geizendorffer, I.R.; Baro, F.; Roche, P.K.; Bondeau, A.; Cramer, W. Impacts of urbanization around Mediterranean cities: Changes in ecosystem service supply. Ecol. Indic. 2018, 91, 589-606. [CrossRef]

11. Hodges, M.N.; McKinney, M.L. Urbanization impacts on land snail community composition. Urban Ecosyst. 2018, 21, 721-735. [CrossRef]

12. Ellis, E.C.; Ramankutty, N. Putting people in the map: Anthropogenic biomes of the World. Front. Ecol. Environ. 2008, 6, 439-447. [CrossRef]

13. Song, S.; Xu, X.P.; Wu, Z.F.; Deng, X.J.; Wang, Q. The relative impact of urbanization and precipitation on long-term water level variations in the Yangtze River Delta. Sci. Total Environ. 2019, 648, 460-471. [CrossRef] [PubMed]

14. Supantha, P.; Subimal, G.; Micky, M.; Anjana, D.; Subhankar, K.; Dev, N. Increased spatial variability and intensification of extreme monsoon rainfall due to urbanization. Sci. Rep. 2018, 8, 3918. [CrossRef]

15. Costa, A.C.; Santos, J.A.; Pinto, J.G. Climate change scenarios for precipitation extremes in Portugal. Theor. Appl. Climatol. 2011, 108, 217-234. [CrossRef]

16. Pyke, C.; Warren, M.P.; Johnson, T.; Lagro, J., Jr.; Scharfenberg, J.; Groth, P.; Freed, R.; Schroeer, W.; Main, E. Assessment of low impact development for managing stormwater with changing precipitation due to climate change. Landsc. Urban Plan. 2011, 103, 166-173. [CrossRef]

17. Xu, Y.-P.; Zhang, X.; Ran, Q.; Tian, Y. Impact of climate change on hydrology of upper reaches of Qiantang River Basin, East China. J. Hydrol. 2013, 483, 51-60. [CrossRef]

18. Mavromatidi, A.; Briche, E.; Claeys, C. Mapping and analyzing socio-environmental vulnerability to coastal hazards induced by climate change: An application to coastal Mediterranean cities in France. Cities 2018, 72, 189-200. [CrossRef]

19. Rubinato, M.; Nichols, A.; Peng, Y.; Zhang, J.; Lashford, C.; Cai, Y.; Lin, P.; Tait, S. Urban and river flooding: Comparison of flood risk management approaches in the UK and China and an assessment of future knowledge needs. Water Sci. Eng. 2019, 12, 274-283. [CrossRef]

20. Shu, A.; Tian, L.; Wang, S.; Rubinato, M.; Zhu, F.; Wang, M.; Sun, J. Hydrodynamic characteristics of the formation and movement processes for non-homogeneous debris-flow. Water 2018, 10, 452. [CrossRef]

21. Shu, A.; Duan, G.; Rubinato, M.; Wang, S.; Zhu, F. Collapsing mechanism of the typical cohesive riverbank along Ningxia-Inner Mongolia catchment along the Yellow River. Water 2018, 10, 1272. [CrossRef]

22. Kumar, A.; Asthana, A.K.L.; Priyanka, R.S.; Jayangondaperumal, R.; Gupta, A.; Bhakuni, S.S. Assessment of landslide hazards induced by extreme rainfall events in Jammu and Kashmir, Himalaya, northwest India. Geomorphology 2017, 284, 72-87. [CrossRef]

23. Alvioli, M.; Melillo, M.; Guzzetti, F.; Rossi, M.; Palazzi, E.; von Hardenberg, J.; Brunetti, M.T.; Peruccacci, S. Implications of climate change on landslide hazard in Central Italy. Sci. Total Environ. 2018, 630, 1528-1543. [CrossRef] [PubMed]

24. Gariano, S.L.; Guzzetti, F. Landslides in a changing climate. Earth Sci. Rev. 2016, 162, 227-252. [CrossRef]

25. Dilley, M.; Chen, U.; Deichmann, R.S.; Lerner-Lam, A.; Arnold, M. Natural Disaster Hotspots: A Global Risk Analysis; Disaster Risk Management Series, 5; The World Bank: Washington, DC, USA, 2005.

26. IPCC. 2014: Climate Change 2014: Synthesis Report. Contribution of Working Groups I, II and III to the Fifth Assessment Report of the Intergovernmental Panel on Climate Change; Pachauri, R.K., Meyer, L.A., Eds.; IPCC: Geneva, Switzerland, 2014; 151p.

27. Campbell, B.M.; Hansen, J.; Rioux, J.; Stirling, C.M.; Twomlow, S.; Wollenberg, E.L. Urgent action to combat climate change and its impacts (SDG13): Transforming agriculture and food systems. Curr. Opin. Environ. Sustain. 2018, 34, 13-20. [CrossRef] 
28. Arfvidsson, H.; Simon, D.; Oloko, M.; Moodley, N. Engaging with and measuring informality in the proposed Urban Sustainable Development Goal. Afr. Geogr. Rev. 2017, 36, 100-114. [CrossRef]

29. Li, G.; Rubinato, M.; Wan, L.; Wu, B.; Luo, J.; Fang, J.; Zhou, J. Preliminary characterization of underground hydrological processes under multiple rainfall conditions and rocky desertification degrees in Karst regions of Southwest China. Water 2020, 12, 594. [CrossRef]

30. Fang, J.; Li, G.; Rubinato, M.; Ma, G.; Zhou, J.; Jia, G.; Yu, X.; Wang, H. Analysis of long-term water level variations in Qinghai Lake in China. Water 2019, 11, 2136. [CrossRef]

31. Ran, Q.; Wang, F.; Gao, J. Modelling effects of rainfall patterns on runoff generation and soil erosion processes on slopes. Water 2019, 11, 2221. [CrossRef]

32. Shu, A.; Duan, G.; Rubinato, M.; Tian, L.; Wang, M.; Wang, S. An experimental study on mechanisms for sediment transformation due to riverbank collapse. Water 2019, 11, 529. [CrossRef]

33. Tang, H.; Ran, Q.; Gao, J. Physics-based simulation of hydrologic response and sediment transport in a hilly-gully catchment with a check dam system on the Loess Plateau, China. Water 2019, 11, 1161. [CrossRef]

34. Tang, H.; Pan, H.; Ran, Q. Impacts of filled check dams with different deployment strategies on the flood and sediment transport processes in a Loess Plateau catchment. Water 2020, 12, 1319. [CrossRef]

35. Feng, Q.; Ho, H.C.; Man, T.; Wen, J.; Jie, Y.; Fu, X. Internal stability evaluation of soils. Water 2019, 11, 1439. [CrossRef]

36. Liang, Q.; Borthwick, A.G.L.; Stelling, G. Simulation of dam and dyke break hydrodynamics on dynamically adaptive quadtree grids. Int. J. Numer. Methods Fluids 2004, 46, 127-162. [CrossRef]

37. Chang, T.J.; Kao, H.M.; Chang, K.H.; Hsu, M.H. Numerical simulation of shallow water dam break flows in open channels using smoothed particle hydrodynamics. J. Hydrol. 2011, 408, 78-90. [CrossRef]

38. Zhang, Y.; Rubinato, M.; Kazemi, E.; Pu, J.H.; Huang, Y.; Lin, P. Numerical and experimental analysis of shallow turbulent flow over complex roughness beds. Int. J. Comput. Fluid Dyn. 2019, 33, 202-221. [CrossRef]

39. Manenti, S.; Wang, D.; Domingues, J.M.; Li, S.; Amicarelli, A.; Albano, R. SPH modeling of water-related natural hazards. Water 2019, 11, 1875. [CrossRef]

40. Pu, J.H.; Hussain, K.; Shao, S.; Huang, Y. Shallow sediment transport flow computation using time-varying sediment adaptation length. Int. J. Sediment. Res. 2014, 29, 171-183. [CrossRef]

41. Wu, Y.; Tian, L.; Rubinato, M.; Gu, S.; Yu, T.; Xu, Z.; Cao, P.; Wang, X.; Zhao, Q. A new parallel framework of SPH-SWE for dam break simulation based on OpenMP. Water 2020, 12, 1395. [CrossRef]

42. Wang, S.; Shu, A.; Rubinato, M.; Wang, M.; Qin, J. Numerical simulation of non-homogeneous viscous debris-flows based on the Smoothed Particle Hydrodynamics (SPH) method. Water 2019, 11, 2314. [CrossRef]

43. Jiang, H.; You, Y.; Hu, Z.; Zheng, X.; Ma, Q. Comparative study on violent sloshing with water jet flows by using the ISPH method. Water 2019, 11, 2590. [CrossRef]

44. Yang, Y.S.; Yang, T.T.; Qiu, L.C.; Han, Y. Simulating the overtopping failure of homogeneous embankment by a Double-Point Two-Phase MPM. Water 2019, 11, 1636. [CrossRef]

45. Pandey, M.; Chen, S.C.; Sharma, P.K.; Ojha, C.S.P.; Kumar, V. Local scour of armor layer processes around the circular pier in non-uniform gravel bed. Water 2019, 11, 1421. [CrossRef]

46. Yang, F.; Shao, X.; Fu, X.; Kazemi, E. Simulated flow velocity structure in meandering channels: Stratification and inertia effects caused by suspended Sediment. Water 2019, 11, 1254. [CrossRef]

47. Maji, S.; Hanmaiahgari, P.R.; Balachandar, R.; Pu, J.H.; Ricardo, A.M.; Ferreira, R.M.L. A review on hydrodynamics of free surface flows in emergent vegetated channels. Water 2020, 12, 1218. [CrossRef]

48. Ma, L.; Sun, R.; Kazemi, E.; Pang, D.; Zhang, Y.; Sun, Q.; Zhou, J.; Zhang, K. Evaluation of ecosystem services in the Dongting Lake wetland. Water 2019, 11, 2564. [CrossRef]

49. Zhou, T.; Dong, Z.; Wang, W.; Shi, R.; Gao, X.; Huang, Z. Study on multi-scale coupled ecological dispatching model based on the decomposition-coordination principle. Water 2019, 11, 1443. [CrossRef]

50. Pu, J.H.; Shao, S. Smoothed Particle Hydrodynamics simulation of wave overtopping characteristics for different coastal structures. Sci. World J. 2012, 2012, 163613. [CrossRef]

51. Wu, S.; Rubinato, M.; Gui, Q. SPH simulation of interior and exterior flow field characteristics of porous media. Water 2020, 12,918. [CrossRef]

52. Xu, G.; Hao, H.; Ma, Q.; Gui, Q. An experimental study of focusing wave generation with improved Wave Amplitude Spectra. Water 2019, 11, 2521. [CrossRef] 
53. Jin, R.; Liu, M.; Geng, B.; Jin, X.; Zhang, H.; Liu, Y. Numerical investigation of vortex induced vibration for submerged floating tunnel under different Reynolds numbers. Water 2020, 12, 171. [CrossRef]

54. Yu, Z.; Hu, Z.; Zheng, X.; Ma, Q.; Hao, H. Aeroelastic performance analysis of wind turbine in the wake with a new Elastic Actuator Line model. Water 2020, 12, 1233. [CrossRef]

55. Zheng, X.; Shao, S.; Khayyer, A.; Duan, W.; Ma, Q.; Liao, K. Corrected first-order derivative ISPH in water wave simulations. Coast. Eng. J. 2017, 59, 1750010. [CrossRef]

56. Kazemi, E.; Tait, S.; Shao, S. SPH-based numerical treatment of the interfacial interaction of flow with porous media. Int. J. Numer. Methods Fluids 2020, 92, 219-245. [CrossRef]

(C) 2020 by the authors. Licensee MDPI, Basel, Switzerland. This article is an open access article distributed under the terms and conditions of the Creative Commons Attribution (CC BY) license (http://creativecommons.org/licenses/by/4.0/). 